International

Medical Society

http://imedicalsociety.org

\title{
Preparation of Phytol-Loaded Nanoemulsion and Screening for Antioxidant Capacity
}

Md. Torequl Islam 1,2,3, Leticia Streck ${ }^{4}$, Márcia Fernanda Correia Jardim Paz 1,2, João Marcelo de Castro e Sousa ${ }^{5}$, Marcus Vinícius Oliveira Barros de Alencar 1,2, Ana Maria Oliveira Ferreira da Mata1,2, Ricardo Melo de Carvalho', Jose Victor de Oliveira Santos ${ }^{1}$, Arnobio Antonio da Silva-Junior ${ }^{5}$, Paulo Michel Pinheiro Ferreira $1,2,6$, Ana Amélia de Carvalho Melo-Cavalcante ${ }^{1,2}$

\section{Abstract}

The study prepared a nanoemulsion with a diterpenoid isoprenoid alcohol called phytol (PYT) and subsequently tested it for antioxidant capacity. For this, PYT-loaded nanoemulsion was prepared by phase inversion method and both PYT-containing nanoemulsion (PNE) and PYT-free nanoemulsion (PFNE) (2-16 $\mu \mathrm{M})$ were tested for antiradical activity (DPPH•: 1,1-dipheny-picrylhydrazyl radical; ABTS •+: azino-bisethylbenzthiazoline-sulfonic acid; $\cdot \mathrm{OH}$ : hydroxyl radical scavenging; $\mathrm{NO} \cdot$ : nitrite oxide radical), lipid peroxidation (LP), reduction potential $(\mathrm{RP})$, and inhibition of hemolysis $(\mathrm{HL})$ in rat erythrocytes in comparison with an $\alpha$-tocopherol analogue (Trolox - TRO - positive control). In addition, an in vivo test was performed with wildtype and deficient Saccharomyces cerevisiae strains using hydrogen peroxide $\left(\mathrm{H}_{2} \mathrm{O}_{2}\right)$ as a stressor. Results suggest that PNE exhibited higher antioxidant than the PFNE. Increasing doses reveled antioxidant capacity in a dose-dependent manner. In the $S$. cerevisiae study, both PFNEand PNE-treated groups exhibited decreased rates of survival with the highest doses, whichever in the presence of stressor increased the survival rates, which indicates antioxidative defense capacity of PYT. In this occasion, PNE exhibited prominent antioxidative defense in the presence of stressor rather than PFNE. In conclusion, PYT exhibited potential antioxidant activity but at high concentration it was toxic to the yeast cells. The production of PYT-nanoemulsions may be relevant to the pharmaceutical sciences.
1 Northeast Biotechnology Network (RENORBIO), Post-graduation Program in Biotechnology, Federal University of Piauí, 64.049-550, Teresina, Brazil.

2 Post-graduation Program in Pharmaceutical Science, Federal University of Piauí, 64.049-550 Teresina, Brazil.

3 Department of Pharmacy, Southern University Bangladesh, 22-Shahid Mirza Lane (E), Academic building-II, 1st floor, 739/A, Mehedibag Road, Mehedibag-4000, Chittagong, Bangladesh.

4 Departament of Pharmacy, Federal Uuniversity of Rio Grande do Norte, 59012-570. Natal-RN, Brazil.

5 Department of Biological Sciences, Federal University of Piauí, 64.049-550, Picos, Brazil.

6 Department of Biophysics and Physiology, Federal University of Piauí, 64.049-550 Teresina, Brazil.

\section{Contact information:}

\section{Md. Torequl Islam.}

Address: Department of Biochemistry and Pharmacology, Post-graduation Program in Pharmaceutical Science, Federal University of Piauí, 64.049-550, Teresina, Brazil.

Tel: 0558681265804.

” rbiotufpi.br@gmail.com

\section{Keywords}

Antioxidant; Radicals; Nanoemulsion; Phytol; Saccharomyces Cerevisiae. 


\section{Introduction}

Oxidative stress results from the reactive oxygen/ nitrogen species (ROS/RNS) and to the damage of essential macromolecules, with apoptosis or necrotic cell death. It is believed that the basic mechanism underlying toxicity may be extracellular reactive species ultimately reaching the nucleus, where it causes DNA damage. Furthermore, DNA damage followed by subsequent cellular proliferation propagates errors and may result in carcinogenesis [1]. Although oxidative DNA damage is repaired by a number of different enzymes, some believe that oxidants and repair enzymes must remain at steady state [2].

Phytol (3, 7, 11, 15-tetrametilhexadec-2-en-1-ol; PYT), along with antioxidant, is already evident to have a number of biological activities, including antimicrobial, antispasmodic, antimutagenic, antibiotic-chemotherapeutic, anticancer, anti-teratogenic, antidiabetic, lipid lowering, anticonvulsant, immunoadjuvancy, antinociceptive, anti-inflammatory, anxiolytic, antidepressant, hair-fall defense and so on [3]. According to Andrade and Fasolo compounds with antioxidant and antimicrobial activities may promote overall health [4]. PYT is still used as a fragrance material in a number of cosmetics and non-cosmetics products [3]. Nowadays extensive research is focusing on the natural products, especially derived from plants, despite of the synthesized medicaments. The use of natural antioxidant compounds as a therapy in diseases related to oxidative stress has gained massive interest for their abilities to quench free radicals and the protection of the body against oxidative stress-induced pathogenesis. It is noteworthy that we have a number of synthetic antioxidants. Having high adverse effects and related other unfavorable factors such as cost, availability, safety and efficacy are the stimulation to search new compounds in this context.

Otherwise, being an essential oil, PYT is a water non-soluble molecule, which limits its application and use in products for humans. So, we prepared PYT-loaded nanoemulsions (PNE), which along with the nanoemulsion-free PYT (PFNE) undergone to investigate the antioxidant capacity in a number of in vitro, ex vivo, and in vivo methods.

\section{Materials and methods}

\section{Reagents and chemicals}

Tween-80 (0.05\%) dissolved in saline solution $(0.9 \% \mathrm{NaCl})$ served as the vehicle. Trolox (6-Hydro$x y-2,5,7$, 8-tetramethylchroman-2-carboxylic acid; TRO) was used as the standard for all in vitro and ex vivo antioxidant assays. PYT, and all the necessary reagents and chemicals used in this study were obtained from Sigma-Aldrich (St. Louis, MO, USA).

\section{Preparation of PNE}

PNE was prepared by the emulsion phase inversion method. Briefly, an oil phase composed of medium chain triglycerides $(1 \% \mathrm{w} / \mathrm{w})$ and a surfactant $(5 \%$ $\mathrm{w} / \mathrm{w}$ ) composed of soy phosphatidylcholine and sodium oleate $(1: 7 \mathrm{w} / \mathrm{w})$ was slowly titrated with an aqueous solution of 2-methylpyrrolidone ( $2 \% \mathrm{w} / \mathrm{v})$ at $70{ }^{\circ} \mathrm{C}$ under constant magnetic stirring $(1,500$ rpm). This was emulsified using a basic Ultra-Turrax T18 equipped with the S $18 \mathrm{~N}-19 \mathrm{G}$ dispersing tool at 11,000 rpm for one minute followed by four minutes at 7,000 rpm. The surfactant mixture that produced transparent colloidal dispersions was selected in a previous study using a pseudo-ternary phase diagram [5].

\section{Analysis of PYT-nanoparticles size distribution and zeta potential measurement}

The mean droplet diameter of the nanoparticles was calculated using the cumulative method of analysis based on the intensity of the light scattered (DLS) in a particle size analyzer (Brookhaven Instruments, USA) at $25{ }^{\circ} \mathrm{C}$ using a wavelength of 659 $\mathrm{nm}$ and $90^{\circ}$ detection angle. The correlation was performed in parallel mode and the data was analyzed using Zeta Plus® Particle Sizing version 3.95 
software. Zeta potential (ZP) measurements were performed using the same equipment applying the same field strength (approximately $5.9 \mathrm{~V} / \mathrm{cm}$ ). Five runs for each sample were used to determine the ZP value using the PALS ZP Analyzer software and the electrophoretic mobility according the HelmholtzSmoluchowski equation. The samples were diluted 1:100 (v/v) with purified water.

\section{Drug loading into the nanoemulsions}

The ability of the nanoemulsions to load PYT was tested by adding an excess of the drug into the oil phase before the emulsification step described above. The samples were stored in a thermostatic bath at $25^{\circ} \mathrm{C}$ and vortexed for one minute followed by 15 minutes in an ultrasonic bath every $12 \mathrm{~h}$ for $72 \mathrm{~h}$. After centrifugation (1000 x g for 15 minutes), the samples were filtered through an acetate membrane $(0.45 \mu \mathrm{m})$ and loaded PYT was analytically determined by UV-Vis spectrophotometry at $239 \mathrm{~nm}$ using the equation from the fitted standard curve plot constructed previously.

\section{Experimental animals}

The HL inhibition test was performed in eight weekold Wister albino rats (Rattus norvegicus; body weight: $180-220 \mathrm{~g}$ ) from the Central Animal House of the Federal University of Piaui, Brazil. The animals were allowed free access to food (Purina, Brazil) and tap water ad libitum and were kept under controlled lighting (12 h dark/light cycles) at $24 \pm 2{ }^{\circ} \mathrm{C}$.

\section{Test sample preparation}

For the in vitro and ex vivo assays, PFNE and PNE were emulsified in $0.05 \%$ tween-80 dissolved in $0.9 \% \mathrm{NaCl}$ at final concentrations ranging from 2-16 $\mu \mathrm{M}$. Standard TRO was also dissolved in the same vehicle to give the same dilutions as PFNE and PNE. For the S. cerevisiae assay, PYT (PFNE and PNE) was adjusted to the same dose as above and in the same vehicle $\mathrm{H}_{2} \mathrm{O}_{2}(10 \mathrm{mM})$ was used as the stressor (STR) in this in vivo study.

\section{In vitro antioxidant activity assays}

\section{DPPH・ scavenging activity}

The test for DPPH • scavenging activity was done using a method slightly modified from that described by Manzocco et al. [6]. Briefly, $0.3 \mathrm{~mL}$ samples with concentrations from 2-16 $\mu \mathrm{M}$ were added to a $2.7 \mathrm{~mL}$ ethanolic solution of DPPH $(0.5 \mathrm{mM})$. After 30 min, the absorbance was measured using a spectrophotometer at $517 \mathrm{~nm}$. A similar concentration of TRO served as the positive control, while only $0.3 \mathrm{~mL}$ vehicle was added to the DPPH solution for the negative control (NC). The blank contained no sample. The DPPH radical scavenging potential was calculated using the following equation:

\section{$\%$ inhibition of DPPH• scavenging =} $\left[\left(A_{b r}-A_{a r}\right) / A_{b r}\right] \times 100$

where $A_{b r}$ is the absorbance of DPPH free radicals before the reaction and $A_{a r}$ is the absorbance of DPPH free radicals after the reaction.

\section{ABTS + decolorization activity}

The ABTS $\bullet+$ decolorization assay was done as described by Seeram et al. [7] with slight modification. ABTS - radicals were produced by adding solid manganese dioxide (80 $\mathrm{mg}$ ) to a $5 \mathrm{mM}$ aqueous stock solution of ABTS in $75 \mathrm{mM} \mathrm{Na}+/ \mathrm{K}+$ buffer $(\mathrm{pH}$ 7.0). Then, $2.8 \mathrm{~mL}$ of the sample was added to $0.2 \mathrm{~mL}$ of $\mathrm{ABTS} \cdot+$ solution. The absorbance was read at $750 \mathrm{~nm}$ after 5 minutes. The percentage of scavenging capacity was calculated as follows:

$\%$ ABTS $\bullet+$ scavenged $=\left[\left(A_{b r}-A_{a r}\right) / A_{b r}\right] \times 100$

where $A_{b r}$ is the absorbance of $A B T S \bullet+$ free radicals before the reaction and $A_{a r}$ is the absorbance of $A B T S \bullet+$ free radicals after reaction with the test samples. 


\section{- $\mathrm{OH}$ scavenging activity}

The ability of test samples to scavenge hydrogen peroxide $\left(\mathrm{H}_{2} \mathrm{O}_{2}\right)$ was determined according to the method described by Ruch et al. [8]. Briefly, a solution of $40 \mathrm{mM} \mathrm{H}_{2} \mathrm{O}_{2}$ was prepared in phosphate buffer (50 mM; pH 7.4). The concentration of $\mathrm{H}_{2} \mathrm{O}_{2}$ was measured spectrophotometrically by determining the absorption at $230 \mathrm{~nm}$. The test samples (2-16 $\mu \mathrm{M})$ and standards were added to the $\mathrm{H}_{2} \mathrm{O}_{2}$ and the absorbance at $230 \mathrm{~nm}$ was determined after 10 minutes. A solution containing phosphate buffer without $\mathrm{H}_{2} \mathrm{O}_{2}$ served as the blank. The percentage of $\mathrm{H}_{2} \mathrm{O}_{2}$ scavenging was calculated using the following equation:

$\% \mathrm{H}_{2} \mathrm{O}_{2}$ scavenged $=\left[\left(\mathrm{A}_{0}-\mathrm{A}\right) / \mathrm{A}_{0}\right] \times 100$

where $A_{0}$ is the absorbance of the control and $A$ is the absorbance of the test sample.

\section{Nitric oxide (NO•) scavenging activity}

To test for $\mathrm{NO} \cdot$ scavenging activity, $0.375 \mathrm{~mL}$ of the test sample (PNE, FNE, and trolox), $1.5 \mathrm{~mL}$ of sodium nitroprusside (10 $\mathrm{mM})$, and $0.375 \mathrm{~mL}$ phosphate buffer saline (PBS; $\mathrm{pH}$ 7.4) was mixed, and then the absorbance $\left(A_{b r}\right)$ was read at $546 \mathrm{~nm}$. After incubating the reaction mixture at $37{ }^{\circ} \mathrm{C}$ for 1 hour, 1 $\mathrm{mL}$ of the solution was mixed with $1 \mathrm{~mL}$ Griess reagent. The reaction mixture was then incubated at room temperature for 30 minutes and the final absorbance $\left(A_{a r}\right)$ was measured at $546 \mathrm{~nm}$. The negative control contained only $0.375 \mathrm{~mL}$ of the vehicle [9]. The amount of $\mathrm{NO} \bullet$ inhibition was calculated by the following equation:

$\%$ inhibition of $\mathrm{NO}$ radical $=$ $\left[\left(A_{b r}-A_{a r}\right) / A b r\right] \times 100$

where $A_{b r}$ is the absorbance of $\mathrm{NO} \bullet$ free radicals before the reaction and $A_{a r}$ is the absorbance of NO free radicals after the reaction with the Griess reagent.

\section{Lipid peroxidation inhibition activity}

The TBARS (thiobarbituric acid radicals) assay was used to measure the quantity of lipid peroxidation activity. Briefly, $0.1 \mathrm{~mL}$ of sample (PFNE/PNE/TRO/ $\mathrm{NC}$ ) was added to $1 \mathrm{~mL}$ homogenized egg yolk $(1 \% \mathrm{w} / \mathrm{v})$ in $20 \mathrm{mM}$ phosphate buffer $(\mathrm{pH} 7.4)$. Lipid oxidation was induced by adding $0.1 \mathrm{~mL}$ of 2,2'-azobis (2-methylpropionamidine) dihydrochloride solution (AAPH; $0.12 \mathrm{M}$ ). The reaction mixture was incubated at $37{ }^{\circ} \mathrm{C}$ for 15 minutes. After cooling, $0.5 \mathrm{~mL}$ of the sample was centrifuged after the addition of $0.5 \mathrm{~mL}$ of trichloroacetic acid (15\%) at $1,200 \times \mathrm{g}$ for 10 minutes. An aliquot of $0.5 \mathrm{~mL}$ from the supernatant was mixed with $0.5 \mathrm{~mL}$ TBA $(0.67 \%)$ and heated at $95{ }^{\circ} \mathrm{C}$ for 30 minutes. After cooling, the absorbance was measured at 532 $\mathrm{nm}$ using a spectrophotometer. The levels of lipid peroxides were expressed as nM of TBARS/mg egg yolk using an extinction coefficient of $1.56 \times 10^{5} \mathrm{~mL} /$ $\mathrm{cm}$. Finally, the results were expressed as the percentage of inhibition of lipid peroxidation [10].

\section{Reduction potential (RP) capacity}

The RP test was conducted using a method described by Oyaizu [11] with the following modifications. A $0.2 \mathrm{~mL}$ sample was added to $0.5 \mathrm{~mL}$ of $0.2 \mathrm{M}$ phosphate buffer (pH 6.6) and $0.5 \mathrm{~mL}$ of $\mathrm{K}_{3} \mathrm{Fe}(\mathrm{CN})_{6}$ $(1 \% \mathrm{w} / \mathrm{v})$ and the reaction mixture was heated at 50 ${ }^{\circ} \mathrm{C}$ for 20 minutes. Then, $0.5 \mathrm{~mL}$ of trichloroacetic acid $(10 \% \mathrm{w} / \mathrm{v})$ was added with constant shaking, followed by the addition of $1.175 \mathrm{~mL}$ distilled water and $0.125 \mathrm{~mL}$ of $\mathrm{FeCl}_{3}(0.1 \% \mathrm{w} / \mathrm{v})$ after 5 minutes. The absorbance of the sample was taken at $700 \mathrm{~nm}$ relative to a blank (without sample) For the NC, only $0.2 \mathrm{~mL}$ of the vehicle was added and the samples were treated similarly. The reducing power capacity activity was calculated as follows:

Reducing potential $(\%)=\left[\left(A_{t s}-A_{b s}\right) / A_{t s}\right] \times 100$

where $A_{t s}$ is the absorbance of the test sample and $A_{b s}$ is the absorbance of the blank. 


\section{Ex vivo antioxidant activity assay}

\section{HL inhibition capacity in rat erythrocytes}

To test the inhibition of $\mathrm{HL}$ induced by $\mathrm{H}_{2} \mathrm{O}_{2}$, blood was collected from the retro-orbital plexus of anaesthetized (sodium pentobarbital $35 \mathrm{mg} / \mathrm{kg}$; intraperitoneal) Wistar rats, and the erythrocytes were prepared for $10 \%$ suspension in PBS $(\mathrm{pH}$ 7.4). Next, $0.15 \mathrm{~mL}$ hydrogen peroxide $(200 \mathrm{mM}$ in PBS; pH 7.4) and $0.2 \mathrm{~mL}$ of the sample solution were added to $0.5 \mathrm{~mL}$ of the $10 \%$ erythrocytes suspension. The reaction mixture was incubated at $37^{\circ} \mathrm{C}$ for 30 minutes and immediately centrifuged at 2,500 rpm for 3 minutes. Next, $0.2 \mathrm{~mL}$ of the supernatant was mixed with $2.8 \mathrm{~mL}$ PBS (pH 7.4) and the absorbance was measured at $475 \mathrm{~nm}$ [12]. For the NC, $0.2 \mathrm{~mL}$ of the vehicle was added. The percent rate of hemolysis was calculated using the following formula, taking into account that hemolysis $100 \%$ was induced by $\mathrm{H}_{2} \mathrm{O}_{2}$ (blank):

$$
\begin{gathered}
\text { Inhibition of hemolysis }(\%)= \\
{\left[\left(\mathrm{Abs}_{\text {blank }}-\mathrm{Abs}_{\text {sample }}\right) \times 100\right] / \mathrm{Abs}_{\text {blank }}}
\end{gathered}
$$

where Abs (blank) is the control absorbance with $100 \%$ hemolysis induced by $\mathrm{H}_{2} \mathrm{O}_{2}$ and reactive Abs (sample) is the absorbance of aliquots containing various concentrations of the sample being studied.

\section{In vivo antioxidant activity}

\section{S. cerevisiae assay}

Previously sub-cultured yeast strains were linearly swabbed onto sterile YEPD media $(0.5 \%$ yeast extract, $2 \%$ peptone, $2 \%$ dextrose, and $2 \%$ bacte- riological agar). Next, $0.01 \mathrm{~mL}$ of either a test sample or control were applied to sterile paper disks and treated accordingly. For sole and co-treated groups, the test samples (PFNE and PNE) and the samples plus STR were added, respectively. NC and STR groups were treated with sterile vehicle $(0.05 \%$ tween-80 dissolved in $0.9 \% \mathrm{NaCl}$ ) or $\mathrm{H}_{2} \mathrm{O}_{2}$, respectively. Treatments were done immediately after swabbing the organisms onto the petri dishes. The dishes were then inverted and kept in an incubator at $35 \pm 1{ }^{\circ} \mathrm{C}$ for $72 \mathrm{~h}$. The inhibition zones (in $\mathrm{mm}$ ) were then measured. They ranged from $0 \mathrm{~mm}$ (full growth) to $40 \mathrm{~mm}$ (no growth), based on radius in the petri-dishes. All treatments were performed in duplicate [13].

\section{Statistics}

Results are presented as the mean \pm standard deviation (SD). For in vitro and ex vivo antioxidant tests, data were analyzed by means of analysis of variance (one-way ANOVA) followed by t-Student-NewmanKeuls's post-hoc test. For S. cerevisiae, one-way Bonferoni's test and two Tukey post-tests were performed by using the GraphPadPrism software (version 6.0), considering $p<0.05$.

\section{Results and discussion}

\section{Preparation and characterization of PNE}

Table 1 summarizes the physicochemical characteristics of the transparent oil-in-water nanoemulsions successfully produced in the absence (VNE) or containing PNE. The colloidal dispersions exhibited small and uniformly distributed droplet sizes, with

\begin{tabular}{|c|c|c|c|c|}
\hline $\begin{array}{l}\text { Formulation code, composition } \\
\text { (NMP, Mygliol } @ 812 \text {, surfactant mixture, Phytol) }\end{array}$ & Diameter $(\mathrm{nm}) \pm S D$ & PdI & $Z P(m V) \pm S D$ & Drug loading (\%) \\
\hline VNE, 0.2:0.1:0.5:0 & $130.2 \pm 17.17$ & 0.185 & $-108 \pm 3.01$ & - \\
\hline PNE, 0.2:0.1:05:0.10 & $245.5 \pm 25.02$ & 0.384 & $-77.8 \pm 2.83$ & 1.55 \\
\hline
\end{tabular}

Table 1. Effect of PYT on droplet size (diameter), zeta potential (ZP) at VNE and drug loading at PNE. 
VNE showing a mean diameter of $130.20 \mathrm{~nm}$ and polydispersity index (Pdl) of 0.185. Drug loading caused the PNE droplet size to increase to a mean diameter of $245.50 \mathrm{~nm}(\mathrm{Pdl}=0.384)$. Both VNE and PNE nanoemulsions showed large negative ZP values. The drug loading was calculated using the linear regression equation, $A=0.0045 C+0.005$, which was extracted from the standard curve. The measured absorbance was substituted for " $\mathrm{C}$ ", expressed as $\mu \mathrm{g} / \mathrm{mL}$ (PYT). The correlation coefficient of the straight line was 0.9999. The maximum PYT loading on the oil-in-water (O/W) nanoemulsions was $1.55 \pm 0.012 \%(n=3)$, which allowed us to produce nanoemulsions containing 1\% w/v (10 mg/ $\mathrm{mL})$ PNE.

Nanoemulsions are commonly stabilized by relatively large amounts of surfactant in order to produce transparent dispersions [14]. In this study, we have produced extraordinarily transparent nanoemulsions with droplet sizes in the range of 130 to $250 \mathrm{~nm}$ using low levels of surfactant (about 5\% $\mathrm{w} / \mathrm{w})$. This was the result of using a suitable surfactant pair, composed of soy phosphatidylcholine and sodium oleate $(1: 7 \mathrm{w} / \mathrm{w})$ associated with the co-solvent 2-methylpyrrolidone ( $2 \% \mathrm{w} / \mathrm{v})$. The effect of surfactant composition [5] and co-solvent ratio [15] on both droplet size and droplet size distribution has been previously described. In addition, the composition of oil phase/surfactant/co-solvent used in this work produced stable nanoemulsions with high negative ZPs, guaranteeing suitable electrostatic resilience against flocculation.

PYT loading contributed to the increased nanoemulsion droplet size, which probably occurred due to PYT solubilizing in the oil phase. In previous studies with microemulsions containing the antitumor drug doxorubicin, we observed similar results, with drug loading increasing the droplet size of the microemulsions [16]. The same effect was also observed for amphotericin B loaded oil-in-water microemulsions [17]. Thus, PYT is a liquid immiscible with water and, as observed with amphotericin B, its solubilization into oil phase contributes to increa- sed droplet size. The mechanism of the latter case is not clear, but the ZP reduction observed for drugloaded nanoemulsions confirmed that PYT also disrupts the surfactant film at the oil-water interface. It is possible that the drug is partially located in this region, which is important for PYT's antioxidant effects.

\section{Antioxidant activity assays}

Although living systems coexist with free radicals by developing diverse mechanisms for adapting them to advantageous physiological functions, excessive production of ROS and RNS are implicated in various diseases [18].

\section{In vitro antioxidant activity assays}

\section{DPPH・ scavenging activity}

The DPPH• test is the most commonly performed assay for determining antioxidant activity by monitoring the decreased absorbance of the test sample. It assesses radical scavenging activity. Trolox, (+)-catechin, ethyl gallate, ascorbic acid, and a-tocopherol are generally used as standards for screening new compounds [19]. Table 2 shows that PNE produced greater inhibitory effect when compared to PFNE for all four doses tested, but the activity was lower than the standard (TRO) treated with the same doses. The highest inhibitions were observed for 16 $\mu \mathrm{M}$ of PFNE, PNE, and TRO and were $50.44 \pm 0.01$, $58.17 \pm 0.01$, and $76.59 \pm 0.01 \%$, respectively. There was a dose-response relationship between the tested doses and inhibition.

\section{$\mathrm{ABTS} \bullet+$ decolorization activity}

The ABTS assay, which monitors the scavenging of ABTS $\bullet+$ is another common method used to test for antioxidant activity. It is a peroxidase substrate upon oxidation in the presence of $\mathrm{H}_{2} \mathrm{O}_{2}$ that generates a metastable radical cation [19]. It confirms that there was improvement in the inhibition capability of PNE in comparison to TRO. The $16 \mu \mathrm{M}$ dose of PNE, or TRO exhibited inhibition of $59.18 \pm 0.01 \%$ and 
Table 2. Antioxidant potential of PFNE/PNE in comparison to controls.

\begin{tabular}{|c|c|c|c|c|c|c|c|c|c|c|c|c|}
\hline \multirow{2}{*}{ Samples } & \multicolumn{3}{|c|}{ DPPH (\% radical scavenge) } & \multicolumn{3}{|c|}{ ABTS (\% radical scavenge) } & \multicolumn{3}{|c|}{ OH (\% radical scavenge) } & \multicolumn{3}{|c|}{ NO (\% radical scavenge) } \\
\hline & PFNE & PNE & TRO & PFNE & PNE & TRO & PFNE & PNE & TRO & PFNE & PNE & TRO \\
\hline $16(\mu \mathrm{M})$ & $50.44 \pm 0.01^{a}$ & $1^{\mathrm{a}} \quad 58.17 \pm 0.01^{\mathrm{a}}$ & $76.59 \pm 0.01^{a}$ & $54.59 \pm 0.01^{\mathrm{a}}$ & $59.18 \pm 0.01^{a}$ & $60.76 \pm 0.01^{a}$ & $50.79 \pm 0.01^{a}$ & $62.75 \pm 0.02^{\mathrm{a}}$ & $69.09 \pm 0.02^{\mathrm{a}}$ & $58.36 \pm 0.01^{a}, b$ & $65.06 \pm 0.01^{a}$ & $74.69 \pm 0.02^{\mathrm{a}}$ \\
\hline $8(\mu \mathrm{M})$ & $43.63 \pm 0.03^{a}$ & \begin{tabular}{l|l}
$3^{a}$ & $34.34 \pm 0.02^{a}$
\end{tabular} & $67.40 \pm 0.01^{\mathrm{a}}$ & $40.03 \pm 0.02^{\mathrm{a}}$ & $39.24 \pm 0.01^{a}$ & $49.58 \pm 0.01^{a}$ & $35.93 \pm 0.03^{a}$ & $36.18 \pm 0.01^{a}$ & $48.75 \pm 0.01^{a}$ & $32.81 \pm 0.01^{\mathrm{a}}$ & $37.11 \pm 0.02^{\mathrm{a}}$ & $48.18 \pm 0.02^{\mathrm{a}}$ \\
\hline $4(\mu \mathrm{M})$ & $39.57 \pm 0.01^{a}$ & $1^{\mathrm{a}} \quad 27.16 \pm 0.01^{\mathrm{a}}$ & $45.21 \pm 0.01^{\mathrm{a}}$ & $22.27 \pm 0.01^{\mathrm{a}}$ & $24.41 \pm 0.02^{\mathrm{a}}$ & $27.71 \pm 0.02^{\mathrm{a}}$ & $30.61 \pm 0.01^{\mathrm{a}}$ & $27.41 \pm 0.01^{\mathrm{a}}$ & $41.56 \pm 0.01^{\mathrm{a}}$ & $23.54 \pm 0.01^{\mathrm{a}}$ & $34.23 \pm 0.01^{a}$ & $39.99 \pm 0.01^{\mathrm{a}}$ \\
\hline $2(\mu \mathrm{M})$ & $31.06 \pm 0.01^{a}, b$ & $a, b \quad 19.49 \pm 0.01^{a}$ & $26.17 \pm 0.02^{\mathrm{a}}$ & $15.73 \pm 0.04^{a}, b$ & $16.06 \pm 0.01^{a}, b$ & $10.36 \pm 0.01^{a}$ & $21.64 \pm 0.01^{\mathrm{a}}$ & $15.82 \pm 0.01^{a}$ & $22.66 \pm 0.01^{a}$ & $12.85 \pm 0.02^{\mathrm{a}}$ & $8.93 \pm 0.01^{a}$ & $36.56 \pm 0.01^{a}$ \\
\hline$N C$ & \multicolumn{3}{|c|}{$2.19 \pm 0.05$} & \multicolumn{3}{|c|}{$1.29 \pm 0.03$} & \multicolumn{3}{|c|}{$0.89 \pm 0.02$} & \multicolumn{3}{|c|}{$1.01 \pm 0.01$} \\
\hline \multirow{2}{*}{\multicolumn{2}{|c|}{ Samples }} & \multicolumn{3}{|c|}{ TBARS (\% inhibition of lipid peroxidation) } & & RP $(\%$ inl & hibition oxidat & ion) & & HL (\% inhibit & tion hemolysis & \\
\hline & & \begin{tabular}{l|l} 
PFNE & -1
\end{tabular} & PNE & TRO & PFI & NE & PNE & TRO & PFNE & & PNE & TRO \\
\hline 16( & & $66.89 \pm 0.01^{a}$ & $74.52 \pm 0.01^{\mathrm{a}}$ & $95.02 \pm 0$. & $64.13 \pm$ & $\pm 0.01^{\mathrm{a}}$ & $87.34 \pm 0.01^{a}$ & $94.09 \pm 0.05^{a}$ & $58.85 \pm 0$ & $.01^{\mathrm{a}}, \mathrm{b}$ & $\pm 0.01^{\mathrm{a}}$ & $65.81 \pm 0.01^{a}, b$ \\
\hline $8(\mu$ & & $50.75 \pm 0.01^{\mathrm{a}}$ & $50.75 \pm 0.01^{\mathrm{a}}$ & $81.56 \pm 0$. & $46.49=$ & $\pm 0.01^{\mathrm{a}}$ & $33.88 \pm 0.01^{\mathrm{a}}$ & $87.71 \pm 0.02^{\mathrm{a}}$ & $30.54 \pm$ & 35.19 & $\pm 0.01^{a}$ & $34.08 \pm 0.01^{a}, b$ \\
\hline $4(\mu$ & & $38.89 \pm 0.01^{a}$ & $38.89 \pm 0.01^{\mathrm{a}}$ & $65.86 \pm 0$. & $38.89=$ & $\pm 0.01^{\mathrm{a}}$ & $77.82 \pm 0.01^{\mathrm{a}}$ & $83.19 \pm 0.03^{a}$ & $22.91 \pm 0$ & 19.37 & $\pm 0.01^{\mathrm{a}} \mathrm{b}$ & $16.76 \pm 0.01^{a}, b$ \\
\hline $2(\mu$ & & $31.72 \pm 0.01^{a}, b$ & $13.91 \pm 0.01^{\mathrm{a}}$ & $16.81 \pm 0$. & $34.44=$ & $\pm 0.01^{\mathrm{a}}$ & $64.47 \pm 0.01^{a}$ & $80.27 \pm 0.05^{a}$ & $10.61 \pm 0$ & 13.59 & $\pm 0.01_{1}^{\mathrm{a} b}$ & $8.01 \pm 0.01^{a}, b$ \\
\hline N & & & $2.11 \pm 0.04$ & & & & $2.03 \pm 0.02$ & & & & \pm 0.02 & \\
\hline
\end{tabular}

${ }^{a} p<0.05$ compared to NC $\left(0.05 \%\right.$ tween 80 in $0.9 \%$ NaCl); ${ }^{b} p<0.05$, compared to TRO (ANOVA and t-Student-Newman-Kewls as post hoc test) PFNE: phytol free with nano-emulsion; PNE: phytol in nano-emulsion; TRO: trolox (standard); values are the mean \pm SD $(n=5)$.

Table 3. $I C_{50}$ of antioxidant potential of PYT and standard (trolox).

\begin{tabular}{|c|c|c|c|c|c|c|c|c|c|c|c|c|}
\hline \multirow{2}{*}{ Parameters } & \multicolumn{3}{|c|}{ DPPH test } & \multicolumn{3}{|c|}{ ABTS test } & \multicolumn{3}{|c|}{$\mathrm{OH}$ test } & \multicolumn{3}{|c|}{ NO test } \\
\hline & PFNE & PNE & TRO & PFNE & PNE & TRO & PFNE & PNE & TRO & PFNE & PNE & TRO \\
\hline $1 C_{50}(\mathrm{mM} / \mathrm{L})$ & $1.39 \pm 0.25$ & $4.14 \pm 0.53$ & $3.14 \pm 0.27$ & $4.23 \pm 0.47$ & $4.50 \pm 0.47$ & $4.20 \pm 0.24$ & $2.76 \pm 0.39$ & $4.77 \pm 0.55$ & $3.26 \pm 0.39$ & $5.17 \pm 0.58$ & $4.76 \pm 0.70$ & $2.72 \pm 0.51$ \\
\hline $\mathrm{Cl}$ & $0.63-3.06$ & $1.34-12.82$ & $2.19-4.14$ & $2.18-8.21$ & $2.19-9.26$ & $3.44-5.13$ & $1.07-7.15$ & $1.87-12.16$ & $1.61-6.62$ & $2.12-12.60$ & $1.73-13.09$ & $0.49-15.14$ \\
\hline$r^{2}$ & 0.96 & 0.85 & 0.98 & 0.94 & 0.93 & 0.99 & 0.89 & 0.89 & 0.93 & 0.90 & 0.88 & 0.75 \\
\hline \multirow{2}{*}{ Parameters } & \multicolumn{4}{|c|}{ TBARS test } & \multicolumn{4}{|c|}{ RP test } & \multicolumn{4}{|c|}{ HL test } \\
\hline & \multicolumn{2}{|c|}{ PFNE } & PNE & TRO & \multicolumn{2}{|c|}{ PFNE } & PNE & TRO & PFNE & \multicolumn{2}{|c|}{ PNE } & TRO \\
\hline $\mathrm{Cl}$ & \multicolumn{2}{|c|}{$0.95-6.71$} & $2.35-7.59$ & $2.30-4.47$ & \multicolumn{2}{|c|}{$0.42-10.27$} & $0.78-1.41$ & $0.01-16.81$ & \multirow{2}{*}{ 2.19-14.49 } & \multicolumn{2}{|c|}{$2.05-7.08$} & $3.52-12.83$ \\
\hline$r^{2}$ & & 89 & 0.95 & 0.98 & 0.8 & & 0.99 & 0.84 & & & 94 & 0.94 \\
\hline
\end{tabular}

$\mathrm{IC}_{50}$ : inhibitory concentration $50 \%$ in $\mu \mathrm{M}$; $\mathrm{Cl}$ : confidence interval; $\mathrm{r}^{2}$ : coefficient of determination 
$60.76 \pm 0.01 \%$, respectively (Table 2 ). There was also a dose-response relationship among the test samples.

\section{- $\mathrm{OH}$ scavenging activity}

The free hydroxyl radical $(\bullet \mathrm{OH})$ generally reacts with polyunsaturated fatty acid moieties of cell membrane phospholipids and causes cellular destruction [20]. Measuring the hydroxyl anionic radical $(-\bullet \mathrm{OH})$ is done similarly to the DPPH and ABTS assays, where $\bullet \mathrm{OH}$ produced from the $\mathrm{H}_{2} \mathrm{O}_{2}$ is scavenged by the sample tested. We found that PNE, rather than PFNE, showed higher inhibition. The greatest inhibition was observed for the highest dose $(16 \mu \mathrm{M})$, resulting in $50.79 \pm 0.01 \%, 62.75 \pm 0.02 \%$, and $69.09 \pm 0.02 \%$ by PFNE, PNE, and TRO, respectively. The $\mathrm{Cl}$ revealed that both PFNE $(\mathrm{Cl}=1.07-$ $\left.7.15 \mu \mathrm{M} ; r^{2}=0.89\right)$ and PNE $(\mathrm{Cl}=1.87-12.16 \mu \mathrm{M}$; $\left.r^{2}=0.89\right)$ had improved activity in comparison to TRO $\left(\mathrm{Cl}=1.61-6.62 \mu \mathrm{M} ; r^{2}=0.93\right.$; Table 3$)$. There was also a dose-response relationship for the tested sample doses.

\section{Nitric oxide (NO•) scavenging activity}

The sodium nitroprusside in the $\mathrm{NO}$ - scavenging test was used as the source of nitric oxide (NO) radical. Under aerobic conditions, $\mathrm{NO}$ reacts with oxygen to produce a stable nitrate $\left(\mathrm{NO}_{3} \bullet-\right)$ and nitrite $\left(\mathrm{NO}_{2}{ }^{\bullet}\right)$ radicals, the quantities of which can be determined using the Griess reagent. In this test, PNE, rather than PFNE, had strong NO• scavenging activity, with an inhibition of $65.06 \pm 0.01 \%$ by the $16 \mu \mathrm{M}$ dose, while TRO by $74.69 \pm 0.02 \%$. However, increasing doses exhibited greater inhibition, thus indicating a dose-response relationship. The Cls for PFNE, PNE, and TRO were 2.12-12.60 $\mu \mathrm{M}\left(\mathrm{r}^{2}=0.90\right), 1.73-13.09 \mu \mathrm{M}\left(\mathrm{r}^{2}=0.88\right)$, and 0.49$15.14 \mu \mathrm{M}\left(r^{2}=0.75\right)$, respectively (Table 3$)$. Since PNE showed strong inhibition of $\mathrm{NO} \bullet$ production, it could have physiologically important roles and could potentially prevent nitrosative stress [21].

\section{Lipid per-oxidation inhibition activity}

In the TBARS assay, lipid peroxidation was detected by measuring the amount of malonyl aldehyde (MDA) formed from unsaturated fatty acids. The more MDA that reacted with thiobarbituric acid (TBA), the stronger the pink coloration of the sample and the greater the absorbance [19]. Lipid peroxidation is usually completed by AAPH (in vitro), but it was strongly inhibited by TRO, followed by PNE and PFNE. The $\mathrm{Cl}$ parameter demonstrates the prominence activity of PNE with a coefficient of 0.95 $\left(r^{2}\right)$ (Table 3). However, in this study, $16 \mu \mathrm{M}$ of PNE and PFNE exhibited inhibition of LP by $74.52 \%$ and $66.89 \%$ respectively. The oxidation/peroxidation of lipids by foreign chemicals is a major cause of liver injury [22]. In this in vitro test, the dose-response relationship and the significant $(p<0.05)$ inhibition of LP suggests PYT has potent antioxidant capacity.

\section{Reduction potential (RP) capacity}

The RP assay is a rapid and sensitive antioxidant test, in which absorbance increases upon formation of a color complex with potassium ferricyanide, trichloro acetic acid, and ferric chloride. An increase in the absorbance indicates antioxidant activity of the test sample [23]. Antioxidants are the reducing agents. According to the Table 2, PNE improved the reduction activity more than PFNE for all of the doses tested. PFNE $(16 \mu \mathrm{M})$ showed a similar reduction capability as the lowest dose of PNE $(2 \mu \mathrm{M})$. The $\mathrm{Cl}$ calculated for PFNE, PNE, and TRO were 0.42$10.27 \mu \mathrm{M}\left(r^{2}=0.82\right), 0.78-1.41 \mu \mathrm{M}\left(r^{2}=0.99\right)$, and 0.01-16.81 $\mu \mathrm{M}\left(r^{2}=0.84\right)$, respectively (Table 3 ). Even though the activity was lower than the TRO, there was a dose-response relationship in all cases. A possible simplified mechanism for the antioxidant activity of PYT is shown in Figure 1.

\section{Ex vivo antioxidant activity assay}

\section{HL inhibition capacity in rat erythrocytes}

Ex vivo $\mathrm{HL}$ was carried out by first treating rat erythrocytes with a lysis agent, $\mathrm{H}_{2} \mathrm{O}_{2}$. Then, $\mathrm{HL}$ in- 
hibition was assessed by measuring the hemoglobin concentration in the reaction [12]. In this study, PFNE proficiently up-regulated erythrocyte membrane stability and, thus, reduced HL. Erythrocyte lysis was decreased by $58.85 \pm 0.01 \%, 43.82 \pm$ $0.01 \%$, and $65.81 \pm 0.01 \%$ after treatment with 16 $\mu \mathrm{M}$ of PFNE, PNE, and TRO, respectively. Oxidative radicals, especially $\mathrm{NO} \bullet$, can bind to $\mathrm{Fe}^{2+}$-bound heme, which alters its physiological functions [24], since free hemoglobin $(\mathrm{Hb})$ is crucial for dissolved oxygen $\left(\mathrm{O}_{2}\right)$ and carbon-di-oxide $\left(\mathrm{CO}_{2}\right)$ respiration during normal metabolic processes. Since PYT exhibited strong $\mathrm{NO} \cdot$ scavenging activity in this study, it may alter the detrimental in vivo effects of this radical. However, the lower inhibition of $\mathrm{HL}$ with PNE may be due to its greater hydrophobicity at high concentration and antioxidant-induced prooxidative effects [25].

\section{In vivo antioxidant activity}

\section{S. cerevisiae assay}

Currently, there is evidence that the body prevents free radical damage [26] using some enzymes and substrates [27]. For example, the dismutation enzyme, superoxide dismutase (SOD), can convert

Figure 1: Simplified possible reducing mechanisms of phytol. (A: Free radical (neutralization) pathways. B: Ionization pathway).

A.

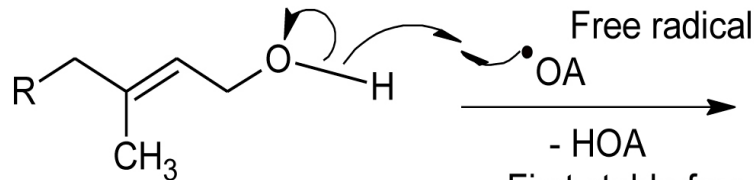

First stable free

Production of hydrogen radical

from the hydroxyl moeity and intitiation of first attack radical product

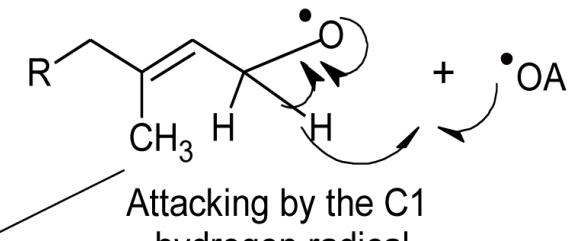

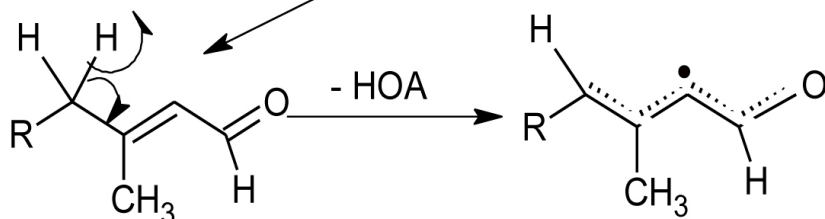

Formation of $\mathrm{C} 4$ hydrogen radical

Formation of stable and subsequent attacking resonance radical

B.

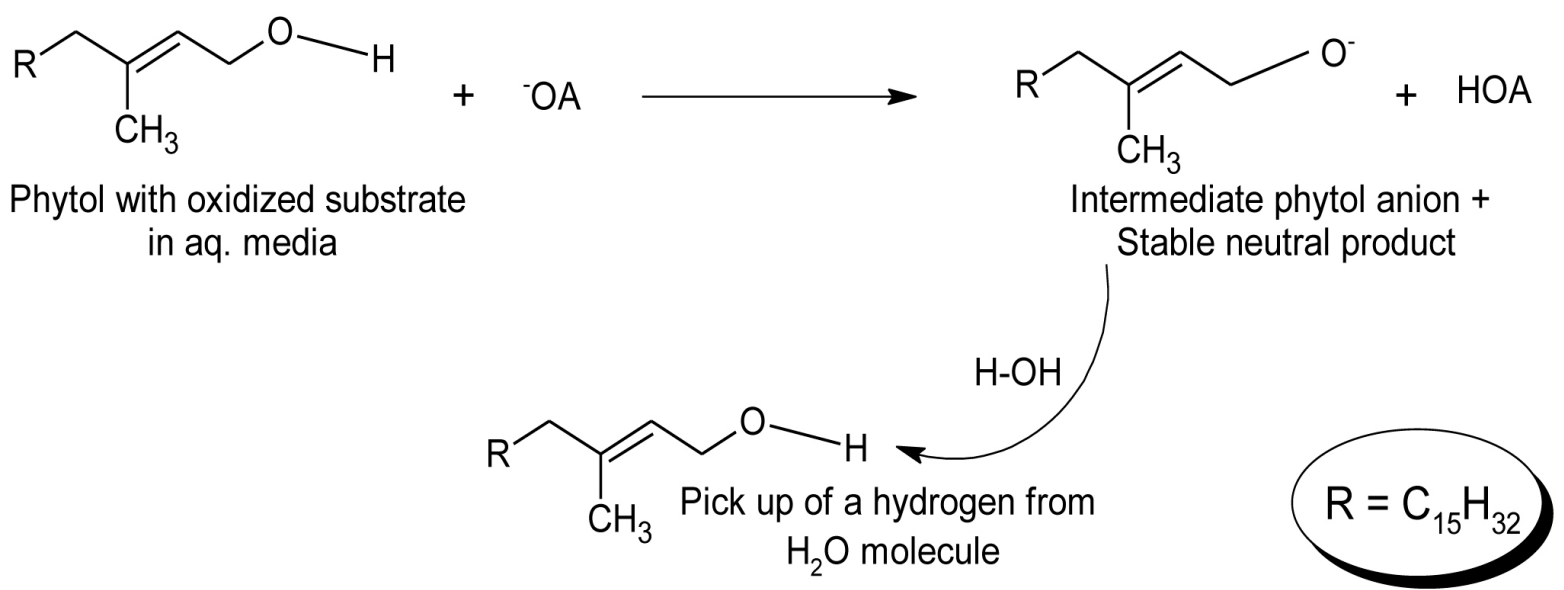


$\mathrm{O}_{2}$ into ordinary oxygen $\left(\mathrm{O}_{2}\right)$ or $\mathrm{H}_{2} \mathrm{O}_{2}$. On the other hand, the catalase (CAT) enzyme, which is ubiquitous in most living organisms, is responsible for converting $\mathrm{H}_{2} \mathrm{O}_{2}$ to water $\left(\mathrm{H}_{2} \mathrm{O}\right)$ and oxygen $\left(\mathrm{O}_{2}\right)$ [28]. These two enzymes are essential for the neutralization of ROS and keeping cells free from oxidative stress-mediated damage [29]. S. cerevisiae have antioxidant compounds in the cytoplasm, mitochondria, and on the entire surface of the cell [30]. In addition, one of its cell wall structural polymers (1-3), (1-6)-b-D-glucan) has antioxidant [31] and immunomodulatory activities [32]. Therefore, this organism can be used to measure the antioxidant action of a wide variety of organic and inorganic substances. In addition, this eukaryotic model allows for the investigation of the effects of antioxidants at the cellular level and is, thus, an attractive alternative to mammalian cell lines. Based on colony formation tests performed by Bakkali et al. [25], certain EOs are cytotoxic to S. cerevisiae, mainly in the stationary growth phase. However, it depends on the state of cell growth as the cells in vegetative stage are much more sensitive due to high penetration power of EOs more efficiently at the budding sites. EOs containing phenolic, aldehyde, and alcoholic $\mathrm{OH}$ are cytotoxic in nature [33] and they may act against fungi [34].

\section{Study-based conclusive talks}

The use of PYT in aqueous dispersions requires a powerful solubilizing strategy, such as O/W nanoemulsion. Previous studies have reported the efficacy of loading insoluble terpenes into nanoemulsions and the increased stability of these mixtures [35]. In addition, an antioxidant synergy formulation (ASF) containing delta, alpha, and gamma tocopherol loaded into nanoemulsions decreased inflammation in CD-1 mice, which was attributed to the increased bioavailability of gamma (2.2 folds) and delta (2.4 folds) tocopherol when compared to pure compounds [36]. The antioxidant activity of the anticancer compound quercetin was also increased when loaded into nanoemulsions, as measured as a function of prophylactic antitumor efficacy against DMBA-induced breast tumors [37]. It was also shown to combat doxorubicin- and cyclosporin A-induced cardiotoxicity and nephrotoxicity [38].

EOs are known for their antioxidant and cytotoxic, rather than mutagenic, activities. At low concentrations, antioxidants cannot penetrate the mitochondrial membrane and, thus, may retain antioxidant, rather than cytotoxic or prooxidant, activities. Low concentrations of retinol and tocopherol exhibit antioxidant and antimutagenic activities, whereas, at high concentration, they are genotoxic [39]. Therefore, both the concentration of the antioxidant and the integrity of the mitochondrial membrane are keys for the antioxidant and cytotoxic activities of the EOs.

Based on the results shown in Table 4, it is clear that PFNE had oxidative activities in Sod $1 \triangle \operatorname{Sod} 2 \Delta$ at all tested doses, but the inhibition zones (7.00$11.00 \mathrm{~mm}$ ) were lower than those seen for the STR (25.25 mm). The PFNE also exhibited an oxidative effect in the SOD-WT and Sod1 $\triangle$ strains at $16 \mu \mathrm{M}$. Survival of the rest of the strains was significantly $(p<0.05)$ increased with the treated doses, where PFNE produced a statistical difference $(p<0.05)$ of $2 \mu \mathrm{M}$ with $16 \mu \mathrm{M}$ in SOD-WT, $2 \mu \mathrm{M}$ and $4 \mu \mathrm{M}$ with $16 \mu \mathrm{M}$ in Sod1 $\triangle, 2 \mu \mathrm{M}$ with $4 \mu \mathrm{M}, 8 \mu \mathrm{M}$ and $16 \mu \mathrm{M}$ in Sod $2 \triangle$ and $2 \mu \mathrm{M}$ with $16 \mu \mathrm{M}$ in Cat1 $\triangle$ strains, respectively.

Table 5 shows that 2-16 $\mu \mathrm{M}$ PNE had an oxidative effect on the Sod $1 \Delta \operatorname{Sod} 2 \Delta$ and $\operatorname{Sod} 1 \Delta$ Cat $1 \Delta$ strains, and 4-16 $\mu \mathrm{M}$ PNE had an effect in the Cat1 $\triangle$ strain, but the inhibition zones were smaller when compared to STR. Only the $2 \mu \mathrm{M}$ dose had an antioxidative effect in Cat1 $\triangle$ when compared to STR. In this case, $16 \mu \mathrm{M}$ PNE also had oxidative activity in the SOD-WT strain. However, there was increased survival rates in the rest of the strains tested. The data presented here suggest no statistical difference between the doses of PNE tested. On the other hand, there was a difference in the results for PFNE and PNE treatments for the Cat1 $\triangle$ and Sod1 $\triangle$ Cat1 $\triangle$ strains. PFNE increased survival rates significantly $(p$ 
Table 4. $I C_{50}$ of antioxidant potential of PYT and standard (trolox).

\begin{tabular}{|c|c|c|c|c|c|c|}
\hline \multirow{2}{*}{ Parameters } & \multicolumn{6}{|c|}{ Inhibition zones in millimeters in test strains } \\
\hline & SOD-WT & Sod1 $\Delta$ & Sod $2 \Delta$ & Cat1 $\triangle$ & Sod1 $\Delta$ Sod2 $\Delta$ & Sod1 $\Delta$ Cat1 $\Delta$ \\
\hline NC $(10 \mu \mathrm{L})$ & $5.00 \pm 1.24$ & $5.50 \pm 1.04$ & $6.25 \pm 0.73$ & $6.75 \pm 0.85$ & $0.50 \pm 0.33$ & $0.25 \pm 0.29$ \\
\hline STR (10 mM) & $20.25 \pm 0.29^{a}$ & $24.50 \pm 1.94^{\mathrm{a}}$ & $24.00 \pm 0.67^{a}$ & $24.00 \pm 2.73^{a}$ & $25.25 \pm 3.57^{\mathrm{a}}$ & $12.75 \pm 0.73^{\mathrm{a}}$ \\
\hline \multicolumn{7}{|l|}{ Nullified STR } \\
\hline $16(\mu \mathrm{M})$ & $7.75 \pm 1.52 \mathrm{a}$ & $10.75 \pm 0.48^{a}$ & $10.25 \pm 0.55$ & $10.75 \pm 0.86$ & $11.00 \pm 0.47^{a}$ & $8.75 \pm 0.99$ \\
\hline $8(\mu \mathrm{M})$ & $6.50 \pm 2.03$ & $9.75 \pm 0.48$ & $9.75 \pm 0.87$ & $9.25 \pm 0.76$ & $8.75 \pm 1.37^{\mathrm{a}}$ & $7.75 \pm 1.19$ \\
\hline $4(\mu \mathrm{M})$ & $7.50 \pm 0.58$ & $9.25 \pm 0.63$ & $9.25 \pm 1.09$ & $8.00 \pm 0.56$ & $8.75 \pm 1.37^{a}$ & $7.00 \pm 0.82$ \\
\hline $2(\mu \mathrm{M})$ & $5.00 \pm 0.67$ & $8.50 \pm 0.29$ & $8.50 \pm 0.75$ & $7.50 \pm 0.74$ & $8.50 \pm 1.00^{a}$ & $5.50 \pm 0.75$ \\
\hline \multicolumn{7}{|l|}{ PFNE+STR } \\
\hline $16(\mu \mathrm{M})$ & $10.25 \pm 0.29^{a}$ & $13.25 \pm 1.89^{a}$ & $7.75 \pm 1.73^{b}$ & $6.50 \pm 1.89^{b}$ & $8.50 \pm 1.00^{a}$ & $8.75 \pm 0.99^{b}$ \\
\hline $8(\mu \mathrm{M})$ & $9.50 \pm 0.33^{b}$ & $7.00 \pm 1.68^{b}$ & $8.25 \pm 0.85^{b}$ & $5.00 \pm 1.58^{b}$ & $7.00 \pm 0.82^{\mathrm{a}}$ & $7.75 \pm 1.19^{b}$ \\
\hline $4(\mu \mathrm{M})$ & $9.50 \pm 1.00^{b}$ & $5.50 \pm 0.87 b, c$ & $7.50 \pm 1.38^{b}$ & $7.50 \pm 1.29^{b}$ & $9.00 \pm 1.25^{a}$ & $7.00 \pm 0.82^{b}$ \\
\hline $2(\mu \mathrm{M})$ & $8.25 \pm 0.73^{b, c}$ & $5.25 \pm 0.75^{b, c}$ & $4.25 \pm 0.73^{b, c, d, e}$ & $3.75 \pm 0.46^{b, c}$ & $8.75 \pm 1.28^{a}$ & $5.50 \pm 0.75^{b}$ \\
\hline
\end{tabular}

Table 5. Inhibition zones of PNE, NC and STR in proficient and mutant S. cerevisiae strains.

\begin{tabular}{|c|c|c|c|c|c|c|}
\hline \multirow{2}{*}{ Parameters } & \multicolumn{5}{|c|}{ Inhibition zones in millimeters in test strains } \\
\cline { 2 - 7 } & SOD-WT & Sod1 $\Delta$ & Sod2 $\Delta$ & Cat1 & Sod1 $\Delta$ Sod2 $\Delta$ & Sod1 $\Delta$ Cat1 $\Delta$ \\
\hline NC $(10 \mu \mathrm{L})$ & $5.00 \pm 1.24$ & $5.50 \pm 1.04$ & $6.25 \pm 0.73$ & $6.75 \pm 0.85$ & $0.50 \pm 0.33$ & $0.25 \pm 0.29$ \\
\hline STR $(10 \mathrm{mM})$ & $20.25 \pm 0.29^{\mathrm{a}}$ & $24.50 \pm 1.94 \mathrm{a}$ & $24.00 \pm 0.67^{\mathrm{a}}$ & $24.00 \pm 2.73^{\mathrm{a}}$ & $25.25 \pm 3.57^{\mathrm{a}}$ & $12.75 \pm 0.73^{\mathrm{a}}$ \\
\hline Nullified STR & & & & \\
\hline $16(\mu \mathrm{M})$ & $9.25 \pm 0.87^{\mathrm{a}}$ & $10.00 \pm 0.82$ & $8.75 \pm 1.09$ & $8.25 \pm 1.19^{\mathrm{a}}$ & $10.25 \pm 0.67^{\mathrm{a}}$ & $9.50 \pm 1.11^{\mathrm{a}}$ \\
\hline $8(\mu \mathrm{M})$ & $8.75 \pm 0.87$ & $8.50 \pm 1.11$ & $9.25 \pm 0.55$ & $8.75 \pm 0.55^{\mathrm{a}}$ & $9.50 \pm 0.75^{\mathrm{a}}$ & $9.25 \pm 0.87^{\mathrm{a}}$ \\
\hline $4(\mu \mathrm{M})$ & $8.25 \pm 0.55$ & $7.00 \pm 0.82$ & $7.50 \pm 1.00$ & $8.25 \pm 0.55^{\mathrm{a}}$ & $8.00 \pm 0.47^{\mathrm{a}}$ & $8.25 \pm 0.87^{\mathrm{a}}$ \\
\hline $2(\mu \mathrm{M})$ & $6.50 \pm 0.75$ & $6.25 \pm 0.55$ & $6.25 \pm 0.55$ & $6.50 \pm 0.58^{\mathrm{a}}$ & $6.25 \pm 0.55^{\mathrm{a}}$ & $7.00 \pm 0.82^{\mathrm{a}}$ \\
\hline PNE+STR & & & & & \\
\hline $16(\mu \mathrm{M})$ & $9.75 \pm 0.85^{\mathrm{a}}$ & $6.25 \pm 0.55^{\mathrm{b}}$ & $7.75 \pm 1.52^{\mathrm{b}}$ & $6.75 \pm 1.79^{\mathrm{a}}$ & $8.25 \pm 0.99^{\mathrm{a}}$ & $7.75 \pm 1.78^{\mathrm{a}}$ \\
\hline $8(\mu \mathrm{M})$ & $7.00 \pm 1.70^{\mathrm{b}}$ & $8.25 \pm 1.28^{\mathrm{b}}$ & $8.00 \pm 1.25^{\mathrm{b}}$ & $6.00 \pm 1.83^{\mathrm{a}}$ & $9.00 \pm 0.94^{\mathrm{a}}$ & $8.50 \pm 1.38^{\mathrm{a}}$ \\
\hline $4(\mu \mathrm{M})$ & $8.00 \pm 0.47^{\mathrm{b}}$ & $7.50 \pm 1.53^{\mathrm{b}}$ & $8.25 \pm 1.59^{\mathrm{b}}$ & $8.25 \pm 0.98^{\mathrm{a}}$ & $6.25 \pm 0.29^{\mathrm{a}}$ & $7.75 \pm 0.73^{\mathrm{a}}$ \\
\hline $2(\mu \mathrm{M})$ & $5.50 \pm 0.33^{\mathrm{b}}$ & $6.00 \pm 1.06^{\mathrm{b}}$ & $5.50 \pm 0.75^{\mathrm{b}}$ & $5.00 \pm 0.82^{\mathrm{b}}$ & $6.00 \pm 0.67^{\mathrm{a}}$ & $6.00 \pm 1.06^{\mathrm{a}}$ \\
\hline
\end{tabular}

a $p<0.05$ compared to NC $\left(0.05 \%\right.$ tween 80 in $0.9 \%$ NaCl); b $p<0.05$ compared to STR $\left(\mathrm{H}_{2} \mathrm{O}_{2}\right)$ (one-way ANOVA followed by Bonferoni's test within $95 \%$ confidence interval); values are the mean \pm SD $(n=4)$.

$<0.05)$, but PNE exhibited oxidative effects at all of the doses tested, except $2 \mu \mathrm{M}$. There may be an effect of the vehicle in which the PYT nanoparticles were emulsified. However, the data presented in both Tables $\mathbf{4}$ and $\mathbf{5}$ suggest lower zones of inhibition for both formulations, which were lower than the STR-treated group. The data shown in Tables 3 and 4 reveal that both PYT formulations effectively protected all S. cerevisiae strains tested, thus demonstrating the antioxidant defense capacities of PFNE and PNE.

However, in the without-STR (nullified) treated groups and groups co-treated with $16 \mu \mathrm{M}$ of PFNE/ PNE, the zones of inhibitions were slightly larger than for the other co-treated doses. There may be a hyperoxy effect; which was eventually minimized 
after the application of STR encountered activity of both the PFNE and PNE. In the in vitro $\bullet \mathrm{OH}$ scavenging test (Table 2$)$, PYT significantly $(p<0.05)$ augmented $\bullet \mathrm{OH}$ scavenging potential, thus the STR in this case produces $\mathrm{OH}$ radicals that may encounter PYT (PFNE/PNE). While the defense increased with decreasing doses of PFNE and PNE, the activity was significant $(p<0.05)$ when compared to the NC and STR-treated groups.

It is clear that, like other aerobes, S. cerevisiae has a number of antioxidant defenses, such as: (i) a cytosolic copper-zinc superoxide dismutase (CuZn-SOD; Sod1) encoded by the SOD1 gene; (ii) a mitochondrial manganese superoxide dismutase (Mn-SOD; Sod2) encoded by the SOD2 gene; (iii) a cytosolic catalase encoded by the CTT1 gene; and (iv) a peroxisomal catalase encoded by the CTA1 gene. However, S. cerevisiae can perform both aerobic and anaerobic metabolism depending on the nature of the carbon source. Under aerobic conditions, $S$. cerevisiae produces energy mainly within its mitochondria using a process similar to that of human cells. According to Costa et al. [40], when wildtype $S$. cerevisiae is exposed to ethanol-generating superoxide $\left(\mathrm{O}_{2} \bullet-\right)$ and $\mathrm{H}_{2} \mathrm{O}_{2}$ during both diauxic and post-diauxic growth and the mitochondrial Sod mutant (Sod2 $\Delta$ ) produces essential protection against oxidative stress. A similar study was suggested while working on L-ascorbic acid by Saffi et al. [41]. In this study, both formulations of PYT protected the cytosolic Sod1 $\triangle$, mitochondrial Sod $2 \Delta$, and liver Cat1 $\Delta$ mutants, which may confirm the potential protection against oxidative damage by PYT.

Previous in vivo studies showed that 6, 12, 24, and $48 \mu \mathrm{M}$ PYT had antioxidant activity in mice. It was also postulated to have significant $\bullet \mathrm{OH}_{,} \mathrm{O}_{2} \bullet$, methoxy radical (root $\mathrm{CH}_{2} \mathrm{O} \bullet$-), carbon-dioxide anion radical $\left(\mathrm{CO}_{2} \bullet\right), \mathrm{NO} \bullet$, and $\mathrm{DPPH} \bullet$ scavenging activities. There is also ex vivo evidence for the antioxidant effects of PYT at doses of 2, 6, 12, and $18 \mu \mathrm{M}$ in Swiss mice [3].
There are compounds [42] (Nunes et al., 2014), including diterpene and carnosic acid $\left(\mathrm{C}_{2} \mathrm{OH}_{28} \mathrm{O}_{4}\right)$, that have antioxidant activity due to the presence of active $-\mathrm{OH}$ groups [43]. There are a number of commercially used natural antioxidants, including some diterpenes- kahweol, cafestol [44], carnosic acid, and carnosol [19], and oxidation products of carnosic acid (rosmanol and isorosmanol) [45]. On the other hand, there are also numerous natural antioxidants with reactive hydroxyl $(-\mathrm{OH})$ groups, including carvacrol, thymol, euginol, isoeuginol, gereniol, caffeic acid, p-cumaric acid, terpein-4-ol, alpha-terpenol, limonen, and p-cymene [46].

PYT is a phenolic EO containing an $\mathrm{OH}$ group at its $\mathrm{C} 1$ position, which is of interest for its antioxidant activity. In addition, an increased number of $\mathrm{OH}$ groups may increase the polarity of diterpenes. Recently, aldehyde, oxime, and ethyl bromocrotonyl derivatives of PYT have been shown to have 2, 4, and 6.5 folds more potent antitubercular activities, respectively [47], thus featuring a better pharmacological profile with synthetic products of PYT.

Plant-based antioxidants (natural) have recently gained popularity due to their role as dietary supplements with minimal side effects. There is no doubt that earlier researches done on PYT are demonstrating its potential antioxidant capacity. Our study is also connecting the earlier reports on this diterpene. Both pure phytol (PFNE) and phytol-loaded nanoemulsions (PNE) in this study exhibited potent antioxidant activities in in vitro, ex vivo, and in vivo assays. In addition, the application of PNE as an innovative nanocarrier with a considerable soluble fraction of the studied terpene in chemical, food, and pharmaceutical industries have been well demonstrated. Nevertheless, earlier information about antioxidant potentials of PYT regarding its antiradical capacity is available for researchers. Results emerging from this study will substantially improve the advances in further non-clinical and clinical settings for a wide range of illnesses related to oxidative stress. Furthermore, PYT in nanopreparation 
(PNE) exhibited better antioxidant activities than its free form (PFNE), which may suggest that emulsion preparation is possible by taking into pharmaceuticals consideration.

\section{Abbreviations}

AAPH: 2,2'-azobis(2-methylpropionamidine) dihydrochloride; ABTS: azino-bis-ethylbenzthiazolinesulfonic acid; CAT/Cat: catalase; DPPH: 1,1-diphenyl2-picryl-hydrazyl; HL: hemolysis inhibition; LP: lipid peroxidation; MDA: malonyl aldehyde; NO: nitric oxide; RNS: reactive nitrogen species; $\mathrm{OH}$ : hydroxyl; OS: organoselenium; PBS: phosphate buffer saline; PFNE: phytol free with nano-emulsion; PNE: phytol in nano-emulsion; PYT: phytol; RBC: red blood corpuscle; ROS: reactive oxygen species; RP: reduction potential; SOD/Sod: superoxide dismutase; SOD-WT: superoxide dismutase-wild type; STR: stressor; TBA: thiobarbituric acid; TBARS: thiobarbituric acid; TRO: 6-hydroxy-2, 5, 7, 8-tetramethylchroman-2-carboxylic acid; YEPD: yeast extract-peptone-dextrose media.

\section{Acknowledgement}

We are really very much thankful to Northest Biotechnology Network RENORBIO for funding this project. We also owe to the Nucleus Pharmaceutical Technology (NTF), at Federal University of Piaui, (Teresina, Brazil) to provide laboratory facilities to conduct this study.

\section{Ethical statement}

This study is conducted under a doctoral project approved by the Ethics Committee of Federal University of Piaui (UFPI), Brazil (\#109/14).

\section{Conflict of interest}

We do declare that we have no conflict of interest.

\section{References}

1. S. Jose, P. Jayesh, A. Mohandas, R. Philip, I. S. Bright Singh. Application of primary haemocyte culture of Penaeus monodon in the assessment of cytotoxicity and genotoxicity of heavy metals and pesticides. Marine Environmental Research 2011; 71: 169-177.

2. L. Risom, P. Møller, S. Loft. Oxidative stress-induced DNA damage by particulate air pollution. Mutation Research 2005; 592: 119-137.

3. M. T. Islam, M. V. O. B. Alencar, K. C. Machado, K. C. Machado, A. A. C. Melo-Cavalcante, D. P. Sousa, R. M. Freitas. Phytol in a pharma-medico-stance. Chemico-Biological Interactions 2015; 240: 60-73.

4. J. M. M. Andrade, D. Fasolo. Polyphenol Antioxidants from Natural Sources and Contribution to Health Promotion. Chapter 20, Polyphenols in Human Health Disease 2014; 1: 253-265.

5. F. Ostertag, J. Weiss, D. J. McClements. Low-energy formation of edible nanoemulsions: Factors influencing droplet size produced by emulsion phase inversion. Journal of Colloid Interface Science 2012; 388: 95-102.

6. L. Manzocco, M. Anese, M. C. Nicoli. Antioxidant properties of tea extracts as affected by processing. Lebens-mittelWissenschaft Und-Technology 1998; 31: 694-698.

7. N. P. Seeram, S. M. Henning, R. Lee, Y. Niu, H. S. Scheuller, D. Heber. Catechin and caffeine contents of green tea dietary supplements and correlation with antioxidant activity. Journal of Agricultural and Food Chemistry 2006; 54: 1599-1603.

8. R. J. Ruch, S. J. Cheng, J. E. Klaunig. Prevention of cytotoxicity and inhibition of intercellular communication by antioxidant catechins isolated from Chinese green tea. Carcinogens 1989; 10: $1003-1008$.

9. I. Marcocci, J. J. Marguire, M. T. Droy-lefaiz, L. Packer. The nitric oxide scavenging properties of Ginkgo biloba extract. Biochemical and Biophysical Research Communications 1994; 201: 748-755.

10. H. Esterbauer, K. H. Cheeseman. Determination of aldehydic lipid peroxidation products: Malonaldehyde and 4-hydroxynonenal. Methods in Enzymology 1990; 186: 407-421.

11. $11 \mathrm{M}$. Oyaizu. Studies on products of browning reactions: antioxidant activities of products of browning reaction prepared from glucosamine. Journal of Nutrition 1986; 44: 307-315.

12. T. K. Girish, P. Vasudevaraju, U. J. S. Prasada Rao. Protection of DNA and erythrocytes from free radical induced oxidative damage by black gram (Vigna mungo L.) husk extract. Food and Chemical Toxicology 2012; 50: 1690-1696.

13. V. Fragoso, N. C. Nascimento, D. J. Moura, A. C. R. Silva, M. F. Richter, J. Saffi. Antioxidant and antimutagenic properties of the monoterpene indole alkaloid psychollatine and the crude foliar extract of Psychotria umbellata Vell. Toxicology in Vitro 2008; 22: 559-566.

14. A. Amani, P. York, H. Chrystyn, B. J. Clark, D. Q. Do. Determination of factors controlling the particle size in nanoemulsions using Artificial Neural Networks. European Journal of Pharmaceutical Sciences 2008; 35: 42-51. 
15. A. H. Saberi, Y. Fang, D. J. McClements. Effect of glycerol on formation, stability, and properties of vitamin-E enriched nanoemulsions produced using spontaneous emulsification. Journal of Colloid Interface Science 2013; 411: 105-113

16. T. P. Formariz, L. A. Chiavacci, M. V. Scarpa, A. A. Silva-Júnior, E. S. T. Egito, C. H. B. Terrugi, C. M. Franzini, V. H. V. Sarmento, A. G. Oliveira. Structure and viscoelastic behavior of pharmaceutical biocompatible anionic microemulsions containing the antitumoral drug compound doxorubicin. Colloids Surfaces B: Biointerfaces 2010; 77: 47-53.

17. K. C. Pestana, T. P. Formariz, C. M. Franzini, V. H. V. Sarmento, L. A. Chiavacci, M. V. Scarpa, E. S. T. Egito, A. G. Oliveira. Oilin-water lecithin-based microemulsions as a potential delivery system for amphotericin B. Colloids Surfaces B: Biointerfaces 2008; 66: 253-259.

18. B. H. Neo, S. Kandhi, M. Ahmad, M. S. Wolin. Redox regulation of guanylate cyclase and protein kinase $\mathrm{G}$ in vascular responses to hypoxia. Respiratory Physiology \& Neurobiology 2010; 174: 259-264.

19. M. Antolovich, P. D. Prenzler, E. Patsalides, S. McDonald, K. Robards. Methods for testing antioxidant activity. Analyst 2002; 127: 183-198.

20. M. N. Alam, N. J. Bristi, M. Rafiquzzaman. Review on in vivo and in vitro methods evaluation of antioxidant activity. Saudi Pharmaceutical Journal 2003; 21: 143-152.

21. A. Carr, M. R. McCall, B. Frei. Oxidation of LDL by myeloperoxidase and reactive nitrogen species-reaction pathways and antioxidant protection. Arteriosclerosis, Thrombosis, and Vascular Biology 2000; 20: 1716-1723.

22. M. Dirlik, A. Karahan, H. Canbaz, M. Caglikulekci, A. Polat, L. Tamer, S. Aydin. Effects of sulfasalazine on lipid peroxidation and histologic liver damage in a rat model of obstructive jaundice and obstructive jaundice with lipopolysaccharideinduced sepsis. Current Therapeutic Research (CTR) 2009; 70: 299-315.

23. G. K. Jayaprakash, R. P. Singh, K. K. Sakariah. Antioxidant activity of grape seed extracts on peroxidation models in-vitro. Journal of Agricultural and Food Chemistry 2001; 55: 1018-1022.

24. S. Archer. Measurement of nitric-oxide in biological models. FASEB Journal 1993; 7: 349-360.

25. F. Bakkali, S. Averbeck, D. Averbeck, M. Idaomar. Biological effects of essential oils - A review. Food and Chemical Toxicology 2008; 46: 446-475.

26. M. Valko, D. Leibfritz, J. Moncol, M. T. Cronin, M. Mazur, J. Telser. Free radicals and antioxidants in normal physiological functions and human disease. The International Journal of Biochemistry and Cell Biology 2007; 39: 44-84.

27. S. Munné-Bosch, M. Mueller, K. Schwarz, L. Alegre. Diterpenes and antioxidative protection in drought-stressed Salvia officinalis plants. Journal of Plant Physiology 2001; 158: 1431-1437.

28. P. Chelikani, I. Fita, P. C. Loewen. Diversity of structures and properties among catalases. Cellulular and Molecular Life Science 2004; 61: 192-208.
29. T. J. A. S. Andrade, B. Q. Araújo, A. M. G. L. Citó, da Silva, J. Saffi, M. F. Richter, A. B. F. Ferraz. Antioxidant properties and chemical composition of technical Cashew Nut Shell Liquid (Tcnsl). Food Chemistry 2011; 126: 1044-1048

30. R. Pinheiro, I. Belo, M. Mota. Oxidative stress response of Kluyveromyces marxianus to hydrogen peroxide, paraquat and pressure. Applied Microbiology and Biotechnology 2002; 58: 842-847.

31. G. Kogan, A. Stasko, K. Bauerova, M. Polovka, L. Soltes, V. Brezova, et al. Antioxidant properties of yeast (1-3)-b-D-glucan studied by electron paramagnetic resonance spectrometry and its activity in the adjuvant arthritis. Carbohydrate Polymers 2005; 61: 18-28.

32. J. Li, D. F. Li, J. J. Xing, Z. B. Cheng, C. H. Lai. Effects of bglucan extracted from Saccharomyces cerevisiae on growth performance, and immunological and somatotropic responses of pigs challenged with Escherichia coli lipopolysaccharide. Journal of Animal Science 2006; 84: 2374-2381.

33. G. Sacchetti, S. Maietti, M. Muzzoli, M. Scaglianti, S. Manfredini, M. Radice, R. Bruni. Comparative evaluation of 11 essential oils of different origin as functional antioxidants, antiradicals and antimicrobials in food. Food Chemistry 2005; 91: 621-632.

34. E. M. Soylu, S. Soylu, S. Kurt. Antimicrobial activity of the essential oils of various plants against tomato late blight disease agent Phytophthora infestans. Mycopathology 2006; 161: 119128.

35. M. Maswal, A. A. Dar. Formulation challenges in encapsulation and delivery of citral for improved food quality. Food Hydrocolloids 2014; 37: 182-195.

36. F. Kuo, B. Subramanian, T. Kotyla, et al. Nanoemulsions of an anti-oxidant synergy formulation containing gamma tocopherol have enhanced bioavailability and anti-inflammatory properties. International Journal of Pharmaceutics 2008; 363: 206-213.

37. A. K. Jain, K. Thanki, S. Jain. Self-nanoemulsifying formulation of quercetin: Implications of pro-oxidant activity on the anticancer efficacy. Nanomedicine: Nanotechnlogy Biology and Medicine 2014; 10: 959-969.

38. S. Jain, A. K. Jain, M. Pohekar, et al. Novel self-emulsifying formulation of quercetin for improved in vivo antioxidant potential: Implications for drug-induced cardiotoxicity and nephrotoxicity. Free Radical Biology and Medicine 2013; 65: 117130.

39. G. Bronzetti, M. Cini, E. Andreoli, L. Caltavuturo, M. Panunzio, C. Della Croce. Protective effects of vitamins and selenium compounds in yeast. Mutation Research 2001; 496: 105-115.

40. V. Costa, M. A. Amorin, E. Reis, A. Quintanilha, P. MoradasFerreira. Mitochondrial superoxide dismutase is essential for ethanol tolerance of Saccharomyces cerevisiae in the postdiauxic phase. Microbiology 1997; 143: 1649-1656. 
41. J. Saffi, L. Sonego, Q. D. Varela, M. Salvador. Antioxidant activity of L-ascorbic acid in wild-type and superoxide dismutase deficient strains of Saccharomyces cerevisiae. Redox Report 2006; 11: 179-184.

42. G. B. L. Nunes, P. R. Policarpo, L. M. Costa, T. G. da Silva, G. C. G. Militão, C. A. Câmara, J. M. B. Filho, S. J. C. Gutierrez, M. T. Islam, R. M. de Freitas. In Vitro Antioxidant and Cytotoxic Activity of Some Synthetic Riparin-Derived Compounds. Molecules 2014; 19: 4595-4607.

43. O. I. Aruoma, B. Halliwell, R. Aeschbach, J. Löliger. Antioxidant and prooxidant properties of active rosemary constituents: carnosol and carnosic acid. Xenobiotic 1992; 22: 257-268.

44. K. J. Lee, J. H. Choi, H. G. Jeong. Hepatoprotective and antioxidant effects of the coffee diterpenes kahweol and cafestol on carbon tetrachloride-induced liver damage in mice. Food and Chemical Toxicology 2007; 45: 2118-2125.

45. S. Munné-Bosch, L. Alegre. Changes in carotenoids, tocopherols and diterpenes during drought and recovery, and the biological significance of chlorophyll loss in Rosmarinus officinalis plants. Planta 2000; 210: 925-931.

46. M. A. Shah, S. J. D. Bosco, S. A. Mir. Plant extracts as natural antioxidants in meat and meat products. Meat Science 2014; 98: 21-33.

47. D. Saikia, S. Parihar, D. Chanda, S. Ojha, J. K. Kumar, C. S. Chanotiya, K. Shanker, A. S. Negi. Antitubercular potential of some semisynthetic analogues of phytol. Bioorganic \& Medicinal Chemistry Letters 2010; 20: 508-512.

Publish in International Archives of Medicine

International Archives of Medicine is an open access journal publishing articles encompassing all aspects of medical science and clinical practice. IAM is considered a megajournal with independent sections on all areas of medicine. IAM is a really international journal with authors and board members from all around the world. The journal is widely indexed and classified Q1 in category Medicine. 